\section{The Relationship Between Hematological Parameters and Mortality in Cardiovascular Patients With Postcardiac Arrest Syndrome}

\author{
Mehmet K. Erol ${ }^{1}$, Nazım Kankılıc ${ }^{2}$, Firdevs Kaya ${ }^{1}$, Ahmet Atlas ${ }^{1}$, Veli Fahri Pehlivan ${ }^{1}$, Basak Pehlivan ${ }^{1}$ \\ 1. Anesthesiology, Harran University, Sanliurfa, TUR 2. Cardiovascular Surgery, Harran University, Sanliurfa, TUR
}

Corresponding author: Mehmet K. Erol, kenanerol970@gmail.com

\begin{abstract}
Background: Post-cardiac arrest syndrome is the insufficiency of cardiac and cerebral functions caused by ischemia after sudden cardiac arrest. We aimed to determine the hematological parameters associated with mortality in the intensive care follow-up of patients with post-cardiac arrest syndrome.
\end{abstract}

Methods: The hematological parameters of 285 cardiovascular patients who were admitted to the emergency department of Harran University Medical Faculty between 2013 and 2018 and followed up in the intensive care unit with post-cardiac arrest syndrome were examined. A total of 85 patients were included in the study. These parameters were recorded as the time of arrival to the emergency department ( 0 hour) and hematological parameters at the $24^{\text {th }}$ and $48^{\text {th }}$ hours of intensive care follow-up.

Results: In the mortality group, albumin (P:0.030), hemoglobin (Hg) (P: 0.049), and hematocrit (HCT) (P: 0.020 ) values in the blood parameters, at the time of admission to the emergency department, were significantly lower than those in the survival group. Red blood cell distribution width (RDW) (P: 0.009) and urea $(\mathrm{P}<0.001)$ values at the time of arrival were higher than the survival group. In the $24^{\text {th }}$ and $48^{\text {th }}$ hours, mean hemoglobin (MCHC) $(\mathrm{P}<0.05)$ values were lower and $\mathrm{RDW}(\mathrm{P}<0.05)$ values were higher in the mortality group compared to the survival group.

Conclusions: In this retrospective validation, low albumin, Hg, HCT, MCHC, and high RDW and urea levels may increase mortality in cardiovascular patients who develop post-cardiac arrest syndrome within the first 48 hours. Correcting these values early may reduce mortality.

Categories: Anesthesiology, Cardiac/Thoracic/Vascular Surgery, Cardiology

Keywords: cardiac arrest, post-cardiac arrest syndrome, red blood cell distribution width, mean cell hemoglobin concentration

\section{Introduction}

Review began 12/24/2019 Review ended 12/25/2019 Published 12/27/2019

\section{๑) Copyright 2019}

Erol et al. This is an open access article distributed under the terms of the Creative Commons Attribution License CC-BY 3.0., which permits unrestricted use, distribution, and reproduction in any medium, provided the original author and source are credited.
Cardiac arrest is a condition characterized by the sudden loss of consciousness caused by inadequate cerebral blood flow and sudden stop of blood circulation as a result of the inability of the heart to contract effectively during systole [1-2]. The number of sudden cardiac deaths per year is defined as 1 in about 1000 people [3]. Cardiac arrest is often associated with mortality and morbidity. Mostly seen in individuals with underlying cardiovascular disease [4-5]. The cause of morbidity and mortality after cardiac arrest is the inadequacy of cerebral and cardiac functions due to prolonged whole-body ischemia called post-cardiac arrest syndrome (PCAS) [6]. Acute tubular necrosis, traumatic liver injury and shock liver, ischemic colitis, pneumothorax, bone marrow embolism, cholesterol embolism, rib fractures, ventilator-associated pneumonia, sepsis, and many other systemic serious complications may develop after cardiopulmonary resuscitation. Post-resuscitation syndrome caused by whole-body ischemia-reperfusion injury is a sepsislike condition and constitutes an inflammatory response characterized by myocardial and adrenal dysfunction and hyper coagulopathy. This leads to hypoperfusion and multiorgan dysfunction [1-4]. Intensive care units are the most important step in the follow-up and survival of critically ill patients with this type of PCAS. It is important to determine the parameters predicting mortality in ICU patients. It is important to make periodic improvements by adjusting each variable to be included in these parameters [7]. The aim of this study was to retrospectively evaluate the relationship between mortality and blood parameters in the intensive care unit of cardiovascular patients who were admitted to the emergency department with sudden cardiac arrest.

\section{Materials And Methods}

Two hundred and eighty-five cardiovascular patients admitted to Harran University Medical Faculty emergency department between 2013-2018 were evaluated. The data of the patients were analyzed retrospectively from hospital records and hospital data processing system. Patients with malignancy, under 18 years of age, infection, recent major surgery, chronic renal failure, chronic obstructive pulmonary 
disease, hematologic diseases, post-cardiopulmonary resuscitation in the emergency department who are ex, cardiopulmonary resuscitation (CPR) duration greater than 40 minutes were excluded from the study. After exclusion, 85 patients were included. Demographic data and length of hospitalization were recorded.

Complete blood counts, biochemical analyzes and blood gas values were recorded in the intensive care units when the patients arrived at the emergency department $(0 \mathrm{~h})$ (T0), at the 24th hour (T1), and 48th hour (T2). All blood values were statistically compared between the mortality and survival groups (Mortality group: Group 1, Survival - ICU Discharge group: Group 2). All steps of the study conformed to the guidelines of the Declaration of Helsinki, and informed consent was obtained from all the participants.

Statistical Package for the Social Sciences; version 18.0 (SPSS Inc., Chicago, IL) program was used for the statistical analysis. The Kolmogorov-Smirnov test was used to evaluate the normal distribution of continuous variables. The Mann-Whitney U test and Student's t-test were used to compare variables. Pearson's and Spearman's correlation tests were used for the correlation analysis. The mean values of all the parameters are presented, together with their standard deviations. A p-value of less than 0.05 was considered statistically significant.

\section{Results}

The mean age of the patients included in the study was $60.50 \pm 18.90$ years. Of the 85 patients, 44 (51.7\%) were male and 41 (48.3\%) were female. 27 patients had hypertension, 18 patients had diabetes and hypertension, 30 patients had coronary artery disease, 10 patients had valvular heart disease. In the comparison between the groups, it was seen that age was significantly higher in the Mortality group (Group$1: 62,30 \pm 18,93$, Group-2: 50,53 $\pm 15,870$ ) (P:0,038). At the time of arrival (0th hour) of the patients, albumin (P: 0.030), hematocrit (HCT) (P: 0.020), hemoglobin (Hg) (P: 0.049), red blood cell distribution width (RDW) (p: 0.009), urea-blood urea nitrogen (BUN) $(\mathrm{p}<0.001)$ values were found to be statistically significant between the two groups. Hemoglobin $(\mathrm{Hg})(\mathrm{P}: 0.041)$ and mean cell hemoglobin concentration $(\mathrm{MCHC})(\mathrm{P}$ : 0.039 ) showed significant differences in the 24th hour. At 48th hour, RDW (P: 0.009) and MCHC (P: 0.028) values were significant parameters. Blood parameter analyses between groups were summarized in Table 1 . The data was normally distributed and significant differences between groups are revealed with correlation analysis. The relationship between hematological parameters and mortality in cardiovascular patients with postcardiac arrest syndrome was investigated. Urea (P: 0.000, r: 0.429) values at arrival time were positively correlated with age, and albumin (p: 0.027, r: -0.245) values at arrival time were negatively correlated with age. Other correlation data are summarized in Tables 2-4. In the analysis, RDW values at arrival time and MCHC values of the 24-48th hour were significantly related with BUN, albumin, HCT and Hg values (P $<0,001)$.

\begin{tabular}{|c|c|c|c|}
\hline & Hospital Mortality Group (n:72) & ICU Discharge Group (n:13) & $\mathbf{P}$ \\
\hline Age (Year) & $62,30 \pm 18,93$ & $50,53 \pm 15,870$ & 0,038 \\
\hline Albumin (g/dl) (O.h) & $2,98 \pm 0,742$ & $3,52 \pm 0,881$ & 0,030 \\
\hline Albumin (g/dl) (24.h) & $2,61 \pm 0,63$ & $2,90 \pm 0,89$ & 0,320 \\
\hline Albumin (g/dl) (48.h) & $2,43 \pm 0,49$ & $2,70 \pm 0,62$ & 0,269 \\
\hline НCT (\%) (O.h) & $39,51 \pm 9,54$ & $46,028 \pm 6,04$ & 0,020 \\
\hline НCT (\%) (24.h) & $38,57 \pm 9,44$ & $43,92 \pm 9,10$ & 0,115 \\
\hline НСТ (\%) (48.h) & $35,72 \pm 8,34$ & $37,82 \pm 7,75$ & 0,487 \\
\hline Hemoglobin (g/dl) (O.h) & $12,57 \pm 2,77$ & $14,25 \pm 2,90$ & 0,049 \\
\hline Hemoglobin (g/dl) (24.h) & $12,09 \pm 2,93$ & $14,27 \pm 3,02$ & 0,041 \\
\hline Hemoglobin (g/dl) (48.h) & $11,09 \pm 2,53$ & $12,29 \pm 2,75$ & 0,201 \\
\hline MPV (fL)(O.h) & $7,38 \pm 1,36$ & $6,65 \pm 2,11$ & 0,249 \\
\hline MPV (fL)(24.h) & $7,75 \pm 1,45$ & $7,31 \pm 1,42$ & 0,406 \\
\hline MPV (fL) (48.h) & $7,84 \pm 1,39$ & $8,58 \pm 1,73$ & 0,256 \\
\hline MCHC (g/dl) (O.h) & $31,60 \pm 1,88$ & $30,98 \pm 4,79$ & 0,419 \\
\hline MCHC (g/dl) (24.h) & $31,38 \pm 1,46$ & $32,47 \pm 1,37$ & 0,039 \\
\hline MCHC (g/dl) (48.h) & $31,13 \pm 1,58$ & $32,40 \pm 1,32$ & 0,028 \\
\hline MCV (fL) (0.h) & $88,686 \pm 9,45$ & $90,42 \pm 5,73$ & 0,524 \\
\hline MCV (fL) (24.h) & $88,23 \pm 13,52$ & $84,91 \pm 10,25$ & 0,127 \\
\hline
\end{tabular}




\section{Cureus}

$\begin{array}{llll}\text { MCV (fL) (48.h) } & 87,76 \pm 10,17 & 87,16 \pm 6,72 & 0,866 \\ \text { RDW (\%) (0.h) } & 13,63 \pm 2,94 & 12,24 \pm 1,98 & 0,009 \\ \text { RDW (\%) (24.h) } & 14,06 \pm 2,63 & 13,23 \pm 3,70 & 0,074 \\ \text { RDW (\%) (48.h) } & 13,71 \pm 2,02 & 11,83 \pm 1,49 & 0,012 \\ \text { Urea(g/dl) (0.h) } & 61,54 \pm 41,84 & 29,75 \pm 21,48 & 0,000 \\ \text { Urea(g/dl) (24.h) } & 88,70 \pm 52,40 & 57,79 \pm 29,15 & 0,051 \\ \text { Urea(g/dl) (48.h) } & 98,15 \pm 68,72 & 65,27 \pm 29,44 & 0,145 \\ \text { Creatinine (g/dl) (0.h) } & 1,56 \pm 1,35 & 1,16 \pm 0,35 & 0,705 \\ \text { Creatinine (g/dl) (24.h) } & 2,07 \pm 1,63 & 1,38 \pm 1,56 & 0,183 \\ \text { Creatinine (g/dl) (48.h) } & 2,10 \pm 2,08 & 2,07 \pm 1,63 & 0,124 \\ \text { Uric acid(mg/dl)(0.h) } & 8,50 \pm 3,29 & 6,68 \pm 2,14 & 0,071 \\ \text { Uric acid(mg/dl) (24.h) } & 8,87 \pm 3,16 & 16,45 \pm 11,95 & 0,028 \\ \text { Uric acid(mg/dl)(48.h) } & 7,16 \pm 3,52 & 3,82 \pm 2,39 & 0,149 \\ \text { CRP (mg/dl) (0.h) } & 6,34 \pm 16,98 & 2,55 \pm 7,08 & 0,058 \\ \text { CRP (mg/dl) (24.h) } & 12,05 \pm 8,86 & 7,90 \pm 6,09 & 0,270 \\ \text { CRP (mg/dl) (48.h) } & 13,44 \pm 9,13 & 15,52 \pm 5,60 & 0,567\end{array}$

\section{TABLE 1: Blood parameter analyses between groups}

HCT: hematocrit; MPV: mean platelet volume; MCHC: mean corpuscular hemoglobin concentration; MCV: mean corpuscular volume; RDW: red cell distribution width; CRP: C-reactive protein.

\begin{tabular}{|c|c|c|c|c|c|c|}
\hline & Albumin (g/dl) & НСТ (\%) & Hemoglobin (g/dl) & RDW (\%) & Creatinine (g/dl) & MCHC (g/dl) \\
\hline Urea(g/dl) & p:0.000 r:-0,478 & p:0.001 r:-0,343 & p:0.001 r:-0,346 & p:0.000, r:0,418 & $p: 0.000 \quad r: 0,481$ & $P>0,05$ \\
\hline HCT (\%) & $\mathrm{p}: 0.000 \quad \mathrm{r}: 0,597$ & - & $\mathrm{p}: 0.000 \quad \mathrm{r}: 0,910$ & p:0.000 r:-0,415 & $P>0,05$ & $P>0,05$ \\
\hline Hemoglobin (g/dl) & $\mathrm{p}: 0.000 \quad \mathrm{r}: 0,577$ & $\mathrm{p}: 0.000 \quad \mathrm{r}: 0,910$ & - & p:0.000 r:-0,489 & $P>0,05$ & $\mathrm{p}: 0.006 \quad \mathrm{r}: 0,294$ \\
\hline Albumin (g/dl) & - & p:0.000 r:0,597 & p:0.000 r:0,577 & p:0.001 r:-0,358 & $P>0,05$ & $P>0,05$ \\
\hline
\end{tabular}

\section{TABLE 2: Correlation analyses (T0)}

HCT: hematocrit; RDW: red cell distribution width; MCHC: mean corpuscular hemoglobin concentration.

\begin{tabular}{|c|c|c|c|c|c|}
\hline \multirow[b]{2}{*}{ Hemoglobin (g/dl) } & \multirow{2}{*}{$\begin{array}{l}\text { Albumin (g/dl) } \\
\text { p:0.000 r:0,616 }\end{array}$} & НСТ (\%) & RDW (\%) & Creatinine (g/dl) & Urea(g/dl) \\
\hline & & $\mathrm{p}: 0.000 \quad \mathrm{r}: 0,979$ & $\mathrm{p}: 0.002$ r:-0,357 & $P>0,05$ & $\mathrm{p}: 0.030 \quad \mathrm{r}:-0,255$ \\
\hline $\mathrm{MCHC}(\mathrm{g} / \mathrm{dl})$ & $P>0,05$ & $P>0,05$ & p:0.000 r:-0,403 & p:0.023 r:-0,265 & p:0.040 r:-0,242 \\
\hline \multicolumn{6}{|c|}{ TABLE 3: Correlation analyses (T1) } \\
\hline \multicolumn{6}{|c|}{ HCT: hematocrit; RDW: red cell distribution width; MCHC: mean corpuscular hemoglobin concentration. } \\
\hline
\end{tabular}




\begin{tabular}{|c|c|c|c|c|c|c|c|}
\hline & $\begin{array}{l}\text { Albumin } \\
\text { (g/dl) }\end{array}$ & НCT (\%) & $\begin{array}{l}\text { Hemoglbin } \\
\text { (g/dl) }\end{array}$ & Urea(g/dl) & $\begin{array}{l}\text { Creatinine } \\
\text { (g/dl) }\end{array}$ & MCHC (g/dl) & RDW (\%) \\
\hline RDW (\%) & $\begin{array}{l}\text { P:0.049 r:- } \\
0,292\end{array}$ & $\begin{array}{l}P: 0.023 \quad r:- \\
0,299\end{array}$ & $\begin{array}{l}P: 0.002 \quad r:- \\
0,392\end{array}$ & $P>0,05$ & $P>0,05$ & $\begin{array}{l}P: 0.001 \quad r:- \\
0,437\end{array}$ & - \\
\hline $\begin{array}{l}\mathrm{MCHC} \\
(g / d l)\end{array}$ & $P>0,05$ & $P>0,05$ & $P>0,05$ & $\begin{array}{l}P: 0.004 \text { r:- } \\
0,373\end{array}$ & $\begin{array}{l}P: 0.016 \quad \text { r:- } \\
0,318\end{array}$ & - & $\begin{array}{l}P: 0.001 \quad r:- \\
0,437\end{array}$ \\
\hline
\end{tabular}

TABLE 4: Correlation analyses (T2)

HCT: hematocrit; RDW: red cell distribution width; MCHC: mean corpuscular hemoglobin concentration.

\section{Discussion}

Albumin binds many substances in the body, transports them and removes free radicals. It can capture multiple reactive oxygen products and reactive nitrogen products. It is also known that it increases antiinflammatory cytokines and is an important extracellular antioxidant [8]. In addition, it plays an important role in the inhibition of platelet activation and aggregation and vascular endothelial apoptosis [9]. Studies have shown a relationship between hypoalbuminemia and increased mortality and morbidity [10-11]. It is also mentioned to be an independent predictor of early heart failure [10]. In our study, the blood values obtained at the first admission of the patients who had mortality, it was observed that albumin values were low (P: 0.030) (Table 1). We think that this may be due to a global systemic ischemia-reperfusion response and subsequent systemic inflammatory response in patients with PCAS. This leads to a degradation resistant to vasoregulation and increased coagulation. Albumin accounts for about 80\% of colloid osmotic pressure, thus increasing the vascular hyper-permeability of the inflammatory state, leading to a decrease in oncotic pressure in patients with hypoalbuminemia and thus a reduction in intravascular volume. This creates insufficient blood flow to vital organs [12]. Therefore, low levels of albumin at the time of arrival of patients with PCAS will increase end-organ damage. Early correction of this value will reduce this damage. In animal studies as evidence of this, albumin supplementation improves cerebral blood flow in cardiac arrest and resuscitation models [13].

Anisocytosis has traditionally been defined as the heterogeneity of erythrocyte volumes. The RDW, which expresses anisocytosis, is a laboratory index that shows the change in red blood cell size in the whole blood count. RDW is calculated by dividing the volume of red blood cells (RBC) by the mean corpuscular volume (MCV) [13]. Studies have shown that RDW is associated with blood inflammation markers such as interleukin-6 and C-reactive protein (CRP). In addition, oxidative stress disrupts erythropoiesis and increases anisocytosis and it has been shown that it causes membrane damage leading to RDW increase and reduces circulating red blood cell half-life [14-15]. High RDW has been associated with poor prognosis in various diseases such as pneumonia, cardiovascular diseases, pulmonary embolism, cancer and cerebral infarction [16]. Recently, RDW has been evaluated as a prognostic marker for short and long term mortality in critically ill patients [17]. Similarly, in our study, high RDW (P: 0.009), low Hg (P: 0.049), low HCT (P:0.020), and a decrease in MCHC (P: 0.039) at 24th hours were observed in patients with mortality (Table 1). It is thought that this is due to the development of systemic inflammation response in patients with sudden cardiac arrest and PCAS and oxidative stress reduces RBC survival and affects bone marrow functions and premature RBCs cause an increase in RDW with increased release of peripheral circulation. Similarly, the decrease in RBC survival can be explained by the same mechanism by causing hemolysis and a related decrease in Hg, HCT and MCHC values [18]. To support this, proinflammatory cytokines have been shown to inhibit erythropoietin-induced erythrocyte maturation and proliferation and reduce erythropoietin receptor expression associated with increased RDW [19].

Glomerular filtration rate (GFR), urea-BUN, and creatinine (Cr) were used to evaluate patients' renal function and fluid status [20]. Both $\mathrm{Cr}$ and urea are filtered from the glomerulus due to their small molecular size. $\mathrm{Cr}$ is rarely absorbed from the tubules and excreted in the urine from the body. Urea is absorbed from the tubules. Urea-BUN also has an important role in glomerular water balance. Urea-BUN is a marker for both neurohormonal activity and renal function because reabsorption of urea varies not only with the renal route but also with endocrine disorders [21]. High urea levels are known to be associated with mortality in cardiovascular disorders [22]. In our study, urea values at the time of admission were higher in patients with PCAS in the group associated with mortality $(61,54 \pm 41,84)$, significantly lower in the group without mortality $(29,75 \pm 21,48)(\mathrm{P}<0.05)$. In addition, it was observed that urea values at 24 th and 48 th hours were higher in the mortality group although not statistically significant (Figure 3). However, the relationship between $\mathrm{Cr}$ values and mortality has not been fully explained. Cr values were similar in both groups from the time of arrival $(\mathrm{P}>0.05)$ (Table 1). The reason for this is thought to be the activation of renin-angiotensinaldosterone and sympathetic nervous systems caused by low cardiac output, renal hypoperfusion, decreased GFR and renal hypoperfusion in patients with PCAS [22]. This also affects serum Cr levels. However, serum $\mathrm{Cr}$ levels may also vary for a variety of reasons (age, sex, muscle mass, and diet, etc.) [23]. This made us think 
that urea-BUN levels in PCAS patients may provide more useful information on mortality compared to $\mathrm{Cr}$.

\section{Conclusions}

Urea-BUN, albumin, HCT, Hg, MCHC, RDW values should be carefully monitored for the first 48 hours in patients with PCAS with cardiac disease. Low Hg, HCT, MCHC and high RDW and urea levels may increase mortality in these patients; we think that early correction of these values may reduce mortality. Further studies on patients with PCAS in the future will increase our knowledge on this subject.

\section{Additional Information \\ Disclosures}

Human subjects: Consent was obtained by all participants in this study. Animal subjects: All authors have confirmed that this study did not involve animal subjects or tissue. Conflicts of interest: In compliance with the ICMJE uniform disclosure form, all authors declare the following: Payment/services info: All authors have declared that no financial support was received from any organization for the submitted work. Financial relationships: All authors have declared that they have no financial relationships at present or within the previous three years with any organizations that might have an interest in the submitted work. Other relationships: All authors have declared that there are no other relationships or activities that could appear to have influenced the submitted work.

\section{References}

1. Binks A, Nolan JP: Post-cardiac arrest syndrome. Minerva Anestesiol. 2010, 76:362-8.

2. Mongardon N, Bouglé A, Geri G, et al.: Pathophysiology and management of post-cardiac arrest syndrome [Article in French]. Ann Fr Anesth Reanima. 2013, 32:779-86. 10.1016/j.annfar.2013.07.818

3. Myerburg RJ, Interian A Jr, Mitrani RM, Kessler KM, Castellanos A: Frequency of sudden cardiac death and profiles of risk. Am J Cardiol. 1997, 80:10F-19F. 10.1016/s0002-9149(97)00477-3

4. Reynolds JC, Lawner BJ: Management of the post-cardiac arrest syndrome. J Emerg Med. 2012, 42:440-49. 10.1016/j.jemermed.2011.09.026

5. Fernandez R, Cano S, Catalan I, et al.: High red blood cell distribution width as a marker of hospital mortality after ICU discharge: a cohort study. J Intensive Care. 2018, 6:74. 10.1186/s40560-018-0343-3

6. Reardon PM, Hickey M, English SW, Hibbert B, Simard T, Hendin A, Yadav K: Optimizing the early resuscitation after out-of-hospital cardiac arrest. J Intensive Care Med. 2019, 5: 10.1177/0885066619873318

7. Metnitz PGH, Moreno RP, Almeida E, et al.: SAPS 3-from evaluation of the patient to evaluation of the intensive care unit. Part 1: objectives, methods and cohort description. Intensive Care Med. 2005, 31:133644. 10.1007/s00134-005-2762-6

8. Matsuyama T, Iwami T, Yamada T, et al.: Effect of serum albumin concentration on neurological outcome after out-of-hospital cardiac arrest (from the CRITICAL [Comprehensive Registry of Intensive Cares for OHCA Survival] study in Osaka, Japan. Am J Cardiol. 2018, 121:156-161. 10.1016/j.amjcard.2017.10.005

9. Xia M, Zhang $\mathrm{C}, \mathrm{Gu}$ J, et al.: Impact of serum albumin levels on longterm allcause, cardiovascular,and cardiac mortality in patients with first on set acute myocardial infarction. Clin Chim Acta. 2018, 477:89-93. 10.1016/j.cca.2017.12.014

10. González-Pacheco H, Amezcua-Guerra LM, Sandoval J, Martínez-Sánchez C, Ortiz-León XA, Peña-Cabral MA, Bojalil R: Prognostic implications of serum albumin levels in patients with acute coronary syndromes . Am J Cardiol. 2017, 119:951-958. 10.1016/j.amjcard.2016.11.054

11. Mc Cluskey A, Thomas AN, Bowles BJ, Kishen R: The prognostic value of serial measurements of serum albumin concentration in patients admitted to an intensive care unit. Anaesthesia. 1996, 51:724-727. 10.1111/j.1365-2044.1996.tb07883.x

12. Nolan JP, Neumar RW, Adrie C, et al.: Post-cardiac arrest syndrome: epidemiology, pathophysiology, treatment, and prognostication: a scientific statement from the International Liaison Committee on Resuscitation; the American Heart Association Emergency Cardiovascular Care Committee; the Council on Cardiovascular Surgery and Anesthesia; the Council on Cardiopulmonary, Perioperative, and Critical Care; the Council on Clinical Cardiology; the Council on Stroke. Resuscitation. 2008, 79:350-379. 10.1016/j.resuscitation.2008.09.017

13. Manole MD, Kochanek PM, Foley LM, et al.: Polynitroxyl albumin and albumin therapy after pediatric asphyxia cardiac arrest: effects on cerebral blood flow and neurologic outcome. J Cereb Blood Flow Metab. 2012, 32:560-569. 10.1038/jcbfm.2011.165

14. Tonietto TA, Boniatti MM, Lisboa TC, et al.: Elevated red blood cell distribution width at ICU discharge is associated with readmission to the intensive care unit. Clin Biochem. 2018, 55:15-20. 10.1016/i.clinbiochem.2018.03.010

15. Patel KV, Ferrucci L, Ershler WB, Longo DL, Guralnik JM: Red blood cell distribution width and the risk of death in middle-aged and older adults. Arch Intern Med. 2009, 169:515-523. 10.1001/archinternmed.2009.11

16. Perlstein TS, Weuve J, Pfeffer MA, Beckman JA: Red blood cell distribution width and mortality risk in a community-based prospective cohort. Arch Intern Med. 2009, 169:588-594. 10.1001/archinternmed.2009.55

17. Hunziker S, Celi LA, Lee J, Howell MD: Red cell distribution width improves the simplified acute physiology score for risk prediction in unselected critically ill patients. Crit Care. 2012, 18:89. 10.1186/cc11351

18. Kim CH, Park JT, Kim EJ, et al.: An increase in red blood cell distribution width from baseline predicts mortality in patients with severe sepsis or septic shock. Crit Care. 2013, 17:282. 10.1186/cc13145

19. Pierce CN, Larson DF: Inflammatory cytokine inhibition of erythropoiesis in patients implanted with a mechanical circulatory assist device. Perfusion. 2005, 20:83-90. 10.1191/0267659105pf793oa 


\section{Cureus}

20. Arihan O, Wernly B, Lichtenauer M, et al.: Blood urea nitrogen (BUN) is independently associated with mortality in critically ill patients admitted to ICU. PLoS One. 2018, 13: e0191697.

10.1371/journal.pone.0191697

21. Aronson D, Mittleman MA, Burger AJ: Elevated blood urea nitrogen level as a predictor of mortality in patients admitted for decompensated heart failure. Am J Med. 2004, 116:466-73.

10.1016/j.amjmed.2003.11.014

22. Horiuchi Y, Aoki J, Tanabe K, et al.: A high level of blood urea nitrogen is a significant predictor for in hospital mortality in patients with acute myocardial infarction. Int Heart J. 2018, 59:263-271. 10.1536/ihj.17-009

23. Kimura K, Morita H, Daimon M, et al.: Utility of cystatin C for estimating glomerular filtration rate in patients with muscular dystrophy. Int Heart J. 2016, 57:386-88. 10.1536/ihj.15-461 